Review Article

\title{
Mapping Knowledge Domains of Integration in BIM-Based Construction Networks: A Systematic Mixed-Method Review
}

\author{
Bin Guo' and Tao Feng ${ }^{1}{ }^{2}$ \\ ${ }^{1}$ Professor, Faculty of Engineering Economics and Management, School of Public Administration, Institute of Management, \\ Xi'an University of Architecture and Technology, Xi'an, Shaanxi 710000, China \\ ${ }^{2}$ Institute of Management, Xi'an University of Architecture and Technology, Xi'an, Shaanxi 710000, China
}

Correspondence should be addressed to Tao Feng; 756783706@qq.com

Received 28 November 2018; Revised 6 March 2019; Accepted 28 April 2019; Published 15 May 2019

Academic Editor: Mohammad R. Hosseini

Copyright ( $\odot 2019$ Bin Guo and Tao Feng. This is an open access article distributed under the Creative Commons Attribution License, which permits unrestricted use, distribution, and reproduction in any medium, provided the original work is properly cited.

\begin{abstract}
Building information modeling-based construction networks (BbCNs) are teams from several professional organizations working together to assume building information modeling- (BIM-) related assignments on BIM-enabled projects. With a view to achieving a better understanding of the knowledge domains on integration in BbCNs, a systematic mixed-method review of the relevant studies published from 2008 to 2018 is conducted in this study. An "integration pentagon" made up of context, process, organization, task, and actor is used as a theoretical lens to identify and construct knowledge maps describing the integration in BbCNs. The study conducts a comprehensive review upon a bibliometric analysis based on 1019 researches into BIM and a qualitative analysis of 42 carefully selected researches into integration in BbCNs. The findings confirm that the solutions provided by these researches to support integration in $\mathrm{BbCNs}$ are altogether technology oriented. The sociotechnical dimensions including context, organization, task, and actor show limitations. More importantly, the major academic contributions of the study lie in offering an objective and systematic analysis of previous researches, revealing the gaps on integration in BbCNs, and advising researchers in future studies regarding the integration pentagon as an all-inclusive analysis tool. These results highlight the status quo of BbCNs knowledge and serve as a dynamic platform to allow other scholars to perform further developments of integration in BbCNs.
\end{abstract}

\section{Introduction}

Applying building information modeling (BIM) in delivering construction projects has been on the rise $[1,2]$. BIM-enabled projects are delivered through using building information modeling-based construction networks (BbCNs), defined as teams comprising specialist organizations that are contracted to execute BIM-related works on these projects [3]. The capability to increase integration in these BbCNs has been essential BIM [4]. Nevertheless, sustaining integration among members with geographic dispersion from various organizations and disciplines within $\mathrm{BbCNs}$ has been regarded to be problematic $[5,6]$ and thus consequently deserving further exploration.

Although the existing research underlines the importance of integration and explores the factors impacting integration in BbCNs [7], the insufficiency application status of integration in practice still makes reference to the gaps in the body of knowledge (BOK) on integration within $\mathrm{BbCNs}[5,8,9]$. At the stage, there is an absence of BOK on integration to guide its development in BbCNs, although Oraee et al. [10] have researched the collaboration in BbCNs. However, it should be emphasized that from the point of view of project management research, the meaning of "collaboration" and "integration" is not consistent, and the "integration" means the synergy of internal systems in a separate unit (that is, the project), which is more responsive to the characteristics of the project $[11,12] . \mathrm{BbCN}$ is a construction network built from a project-based unit, and it is more necessary to study its integration characteristics. This discovery induces a great obstacle in determining the direction for research on integration in BbCNs, which 
make it difficult to capture frontier highlight or repetitive efforts.

Accordingly, it is urgent to integrate the existing literature, which might fill the gap and indicate future research highlights [13]. To this end, we draw on the research method of the article of Oraee et al. [10] which was published in the International Journal of Project Management (IJPM) in 2017 and analyze the scholarship on integration in BbCNs. In addition, unlike the study of Oraee et al. [10], this research provides an extended version of an extended Leavitt sociotechnical model as the theoretical point to map and analyze the status of existing literatures on the integration in BbCNs. The results are likely to grasp the connotation and characteristic of integration research in $\mathrm{BbCNs}$ and reveal the concepts and patterns which have been maintained hidden on this topic. Moreover, the findings will play a positive role in guiding and promoting theoretical research and practical application in this field.

The paper starts with a brief explanation of integration within BbCNs, which is followed by the research method. Research findings are then outlined. In the subsequent section, a discussion of those findings is introduced. The paper folds with a summary of the major points and conclusions.

\section{Background}

2.1. Integration on Construction Projects. Integration refers to the process of integrating isolated elements or things into an organic whole. The concept of integrated management was first proposed and applied from the information technology (IT) industry and later developed into a field of expertise in project management. In this new management concept and method, integrated concepts are leveraged to guide and manage practical activities [14]. A traditional management mode derives from the theory of division of labor, while this new approach highlights integration thought, and it also fuses and amplifies individual advantages so that improved comprehensive efficiency, along with management activities, is ensured.

An integrated implementation relies on close communications between project participants [15-18]. With the occurrence of CIM (computer integrated manufacturing) propagation and applications of IT into construction activities [19], the essence of integration has experienced a thorough variation over the past few years $[20,21]$. In nature, BIM has evolved into the core of cross-organization integration technology to support integration of participants [22]. As BIM is developed into a state-of-the-art technology to facilitate integration in the construction industry, BbCNs appear as a major carrier to foster integration $[2,5,9]$ as described below.

2.2. BIM-Based Construction Networks (BbCNs). BIM is a solution to multiparty coordination of innovative technology, and its value depends on a rational organization pattern. Solihin et al. [23] even believe that the traditional project organization model fails to make BIM meet project requirements. Under such circumstances, scholars recognize the necessity of studying the cross-organization application of BIM and putting forward the BbCNs [2]. As BbCN is proposed, construction projects have essentially transitioned to "temporary social networking organizations," [24] indicating that project participants are exposed to a new integration environment. The attainment of the goal and success in BbCNs depends on a closely integrated working and seamlessly information sharing of participants [19, 25-27]. Therefore, many scholars emphasize that we should cultivate the integration environment to transform our traditional ideas so as to better foster integration among $\mathrm{BbCN}$ participants $[8,28,29]$. Integration of construction and $\mathrm{BbCNs}$, however, is a complicated system manipulated by many elements $[8,28]$. It underlines the necessity of an in-depth analysis by combining the characteristics of integration and the BbCNs [30].

2.3. Theoretical Lens. As recommended by Merschbrock et al. [15], a theoretical lens was applied to translate the findings into understandable messages. This theoretical lens assists researchers in developing explanations so that audiences are allowed to relate the findings to broader aspects and findings are made comparable to other cases. Selecting a theoretical lens enhances the internal validity of findings in the cases of studies through a pattern matching in which researchers compare patterns in established theories with empirically observed patterns [31].

Such systems, including BbCNs, are defined by sociotechnical system (STS) theories as organizational work systems consisting of two subsystems, both socially and technically, that interact with and influence each other [32]. These subsystems integrate effectively with each other provided that the interdependency of the subsystems is clearly recognized $[32,33]$. This premise is deemed valid for investigation integration in BbCNs [34] and has provided a theoretical basis for this study.

Sackey et al. [35] reviewed the existing theoretical models to select the most workable for analyzing BbCNs. They concluded that the Leavitt sociotechnical model [36], stereotype though, has evolved adequately and embodies key principles that vividly reflect the working nature in BbCNs. The model has been referred to for a long time in studying technology applications and shows validity in explaining the challenges modern STSs meet [37]. The Leavitt sociotechnical model is associated with technology, task, actor, and organization dimensions. The predictive power of the model, however, grows with the inclusion of new dimensions for specific BbCNs [35, 37]. In the context of innovation, Poirier et al. [38] added several dimensions as process, context, and team to increase the explanatory power of the model in dealing with modern teams. Sackey et al. [35] extended the model in construction by introducing several analytical concepts to produce a modified model that effectively reflects BIM-related systems.

2.4. Integration Pentagon of $B b C N s$. In this study, according to the Leavitt sociotechnical model by Leavitt [36] and the 
extended framework proposed by Poirier et al. [38], an extended Leavitt sociotechnical model has been regarded as a so-called integration pentagon of $\mathrm{BbCNs}$ as shown in Figure 1.

As defined by prior researches, context dimension refers to the specific environment that all these dimensions are set within [38]. Actor dimension involves members of an organization who carry out the work. Process dimension refers to tools and inventions, and it also possesses a functional dimension $[39,40]$. As highlighted in Figure 1, technology and process together compose the technology subset, while other dimensions belong to the social subset in a BbCNs [32]. Organization dimension refers to the common relational system of $\mathrm{BbCNs}$, as shown in Figure 1. Structure and term dimensions have been synthesized into the organization dimension. Task dimension represents the characteristics of $\mathrm{BbCNs}$ activities tasks to be completed.

Thus, the system of integration in $\mathrm{BbCNs}$ comprises several actors, who use a range of tools and technologist to share their expertise and skills in a context of openness, trust, and mutual respect. They jointly work on the tasks that meet their common goal. The core premise embedded in this system is that all five dimensions are highly interrelated in a nondeterministic manner. These dimensions together lend a transformation of integration process and so on and ultimately catalyze the deeper integration in BbCNs [33]. The precondition has formed the pattern of integration pentagon that synthesizes five interrelated dimensions with reciprocal interactions. The integration pentagon shown in Figure 1 is adapted as the theoretical lens in this research, which provides a criterion to analyze where the gaps regarding integration in $\mathrm{BbCNs}$ are.

2.5. Research Methods. To reach the research objective, a "systematic mixed-methods review" has been used to identify the existing studies, research directions, and gap integrations in BbCNs. Systematic review is a tried and tested method, which is normally counted as superior in the matter of transparency. Compared with systematic ways for flagging up literature reviews, this method can easily be verified through replicating the research setting by other researchers. Aarseth et al. [41], however, pointed out that examining the bibliographic sources only by a review might be of bias, as it leads to subjective judgment and interpretation. Therefore, it is necessary to adopt a systematic mixed-method review in synthesizing literature to ensure breadth and depth in understanding [42]. The systematic mixed-method review synthesizes quantitative and qualitative research to collect and review the available literature on the topic of integration in $\mathrm{BbCNs}$, integrating both the automatic and manual search strategies. To collect as many relevant published research papers, automatic and manual search strategies are turned to.

2.6. Data Collection. By providing a comprehensive and objective summary of the academic research achievements

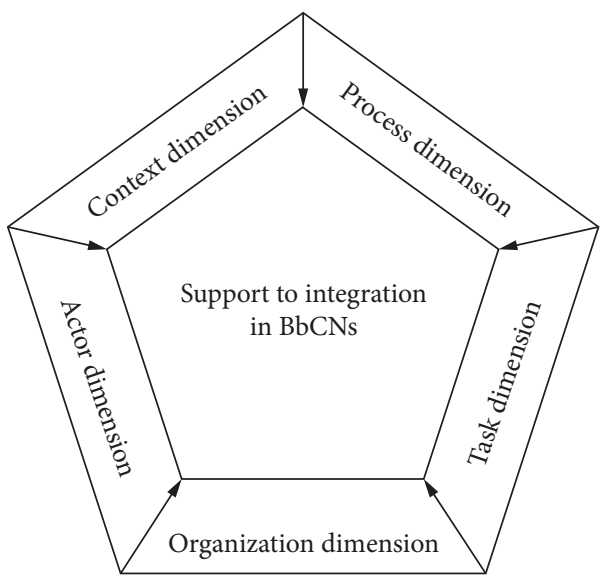

FIGURE 1: The principal knowledge domains (integration pentagon) of BbCNs: a theoretical lens in this study.

in the field of BIM and BIM-enabled projects over the past decade, we use the authoritative academic database web of science (WoS) as the main retrieval platform in this study. The database contains more than 12,000 journals worldwide, which was considered to be sufficient for a broad review on the integration in BbCNs.

2.7. Bibliographic Analysis. In the first stage, a bibliometric analysis method was adapted to review the available studies on BIM-mentioning integration. In this step, common word analysis and common citation analysis were made to explore the distribution and individual signs of literatures in a knowledge domain [43]. This enables researchers to analyze the intellectual landscape of a research area and fulfill their research objectives. There exists a wide range of computer programs for the bibliometric analysis, including VOSviewer, Cite-space, and Gephi. Results from previous researches have offered evidence possible to select computer programs for the bibliometric analysis, and the most important advantage of VOSviewer is that its outputs are closer to the data of WoS [44]. Therefore, VOSviewer has been applied for bibliometric analysis hereafter.

2.8. Qualitative Analysis. In qualitative analysis, what matters is to identify the findings various studies make and any respective gaps by comparing the notions, theories, and themes in a number of retrieved documents. The theoretical lens (integration pentagon) facilitates quantitative analysis in this study by serving as a classification code to classify the retrieved documents. The process of qualitative analysis follows the objective proposed by Gough [26] for qualitative phases in mixed.

\section{Findings of the Study}

3.1. Bibliometric Analysis of the Literature on Integration in BIM. To examine the attention level of integration in the field of BIM-related literature from a more comprehensive perspective, the first step in this study is retrieving the BIMrelated studies from WoS. The selected results were all 
academic papers published during the past decade (20082018), with title/abstract/keywords including the terms of "building information modeling," "building information modeling," and "building information modal." The "BIM" was not set as the search keyword because papers of other disciplines that are not within the scope of this study might appear [45]. A total of 1019 BIM-related documents were retrieved as of February 2018. These papers were downloaded and used as core data to support the subsequent analysis in this study.

It has widely been accepted to use citation analysis as an important method to recognize the most influential literature in the field of BIM [46]. Therefore, the data of selected 1019 papers were uploaded to VOSviewer to establish a network of studies based on citations. As suggested by Riaz et al. [46], "fractional counting" served as a counting approach to minimize the influence of sources with plenty of citations on the network [10]. To ensure that the most influential literature can be identified in BIM, the least number of citations in one publication was set as 10 . There were 35 papers meeting the threshold and thus were put in the network which is created based on connections and is shown in Figure 2.

Font size distinguishes the degree of citation concentration where larger size represents the higher level of citations concentration. The color of these nodes was set according to the level of the citation concentration, with red being the highest level. The literatures adjacent to the center of the network, as presented in Figure 2, are those with high level of citations, which are information sources and representative view of reference on BIM. An in-depth analysis on these works reveals that these BIM-related influential researches not necessarily focus on integration. Therefore, it can be deduced form Figure 2 that although integration is an important concept in BIM performance, it is not yet the mainstream research direction in BIM-related studies.

The second step in this study is retrieving the relevant studies with regard to integration within the corpus of BIM from the database set in the first step. The target publications were identified through the "searching within results" function of WoS. The function was served through setting integration as a target term in the keyword/abstract/title of the identified list of research papers on BIM (1019 researches). While retrieving, we filtered the results by using the following combinations of terms: "collaboration" OR "interoperability" OR "integrated" OR "coalitions" OR "interaction" OR "coordination" OR "process integration" OR "technology integration" OR "system integration" OR "partner integration" OR "customer integration" OR "supplier integration" OR "manufacturing integration" OR "information integration" OR “interoperability". Accordingly, the number of documents retrieved dropped from 1019 to 90 (ended in February 2018). All of these 90 BIMrelated papers regard the integration on their keyword/ abstract/title in varying degrees.

A clear display of the main outlets for publishing researches might contribute to offer a more comprehensive perspective to capture the present research state of integration in BbCNs. The VOSviewer was thus utilized to extract and establishes a source network of main outlets from the dataset which was formed by the second step. In the course of operation, the "analysis type," "analysis unit," and "count method" were set to "citations," "sources," and "fractional counting," respectively. In the network, 79 sources in total were defined. With the least number of documents and citations for each source was set at 2 and 1, respectively, with 38 sources meeting these criteria contained in the source network of main outlets. The network also presents the information flow between nodes, which indicates the citation strength of the data. The tightness of links and the size of nodes suggest the relative impact of the node and the intensity of their respective connections [46].

According to the network shown in Figure 3, the most frequently cited journal in this collection is "Automation in Construction," which was identified as the most effective channel on this topic. From the arrow directions in this network, the information flow begins with "Automation in Construction" as a source of citations. The published papers in this journal generally are based on the researches focusing on technology, software, integrated technologies, and automation. This reveals the fact that the effective outlets hitherto are highly technology oriented, while journals focusing on professional issues, management, construction, and education are less influential in terms of the integration in BIM. Just as contended that the BIM study is almost entirely driven from the perspective of technology.

As a result, available researches, technology oriented on researches into BIM, have not addressed project management and managerial features of integration. These findings point out that enhancing integration in $\mathrm{BbCNs}$ is still considered as a technical matter, despite that researchers increasingly value the key role of managerial components in BbCNs.

To comprehend the contents mentioned in researches connected with integration in BbCNs, the cooccurrence network of keywords was established from the dataset containing 90 documents. "Authors keywords" rather than all keywords were applied to create visualization. The method of "fractional counting" allowed us to extract 454 keywords from the dataset. The least occurrence number of keywords is set at 5, and it resulted in a cooccurrence network of 51 terms with 178 links. As Lee and Yu [20] said, the author keywords present the core of the research, and the key point of the survey was selected by authors carefully. Therefore, the cooccurrence network of keywords shown in Figure 4 demonstrates the highlights of research covered by the literature included in the dataset.

The idea of the PageRank algorithm originates from the mechanism of citation indexing. The more the papers are cited by the more authoritative papers, the more valuable these papers are. This algorithm allows us to rank the nodes based on their importance in the network. From the distance between the nodes and the strength of those links (Figure 4), it is seen that everything highlighted here is BIM or expansions of BIM, while integration was found to be associated only with the node of benchmark, construction, and information technologies. The size of the node also represents the degree of recognition, abd the results drawn 


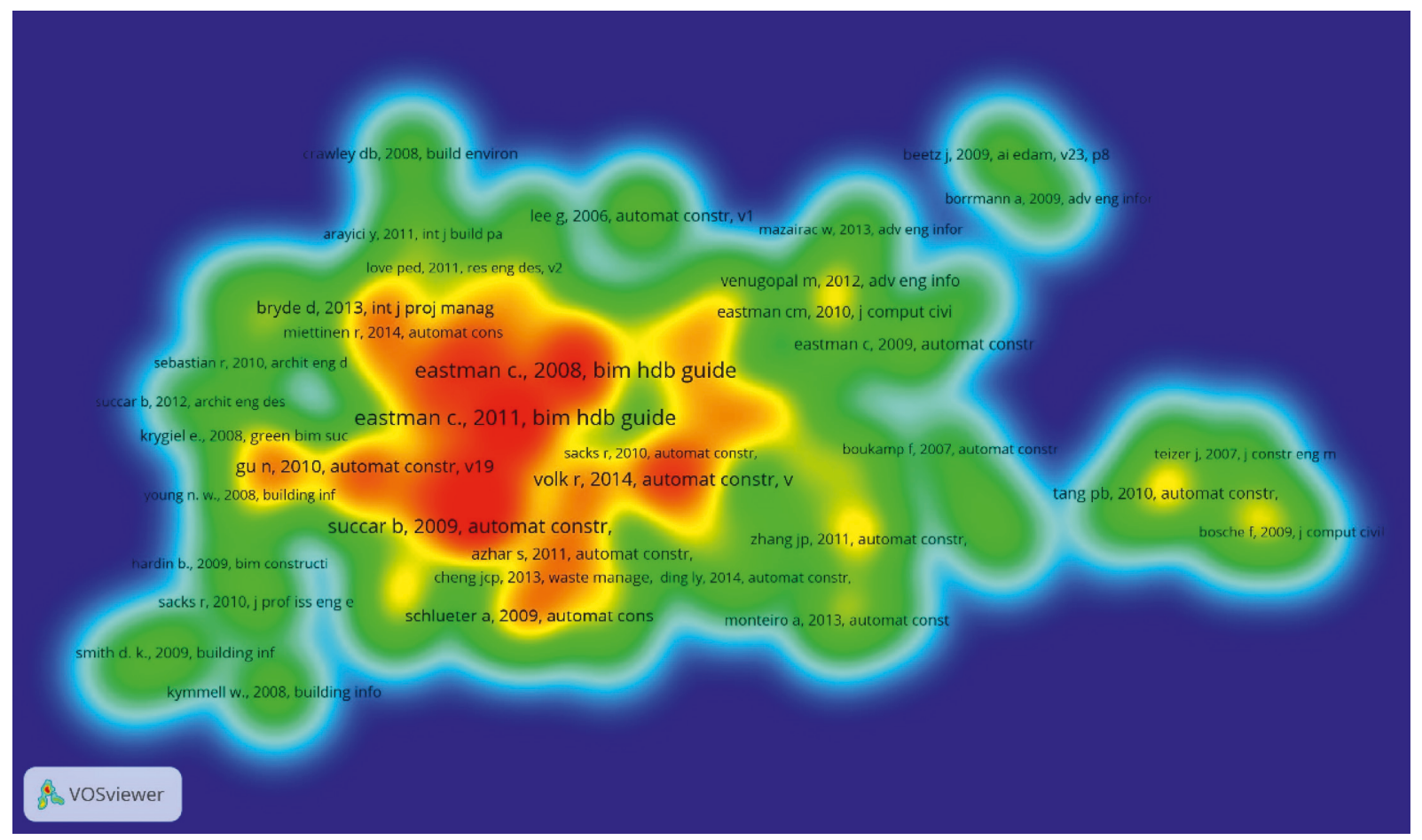

FIGURE 2: Most influential studies in BIM field: 2008-2018.

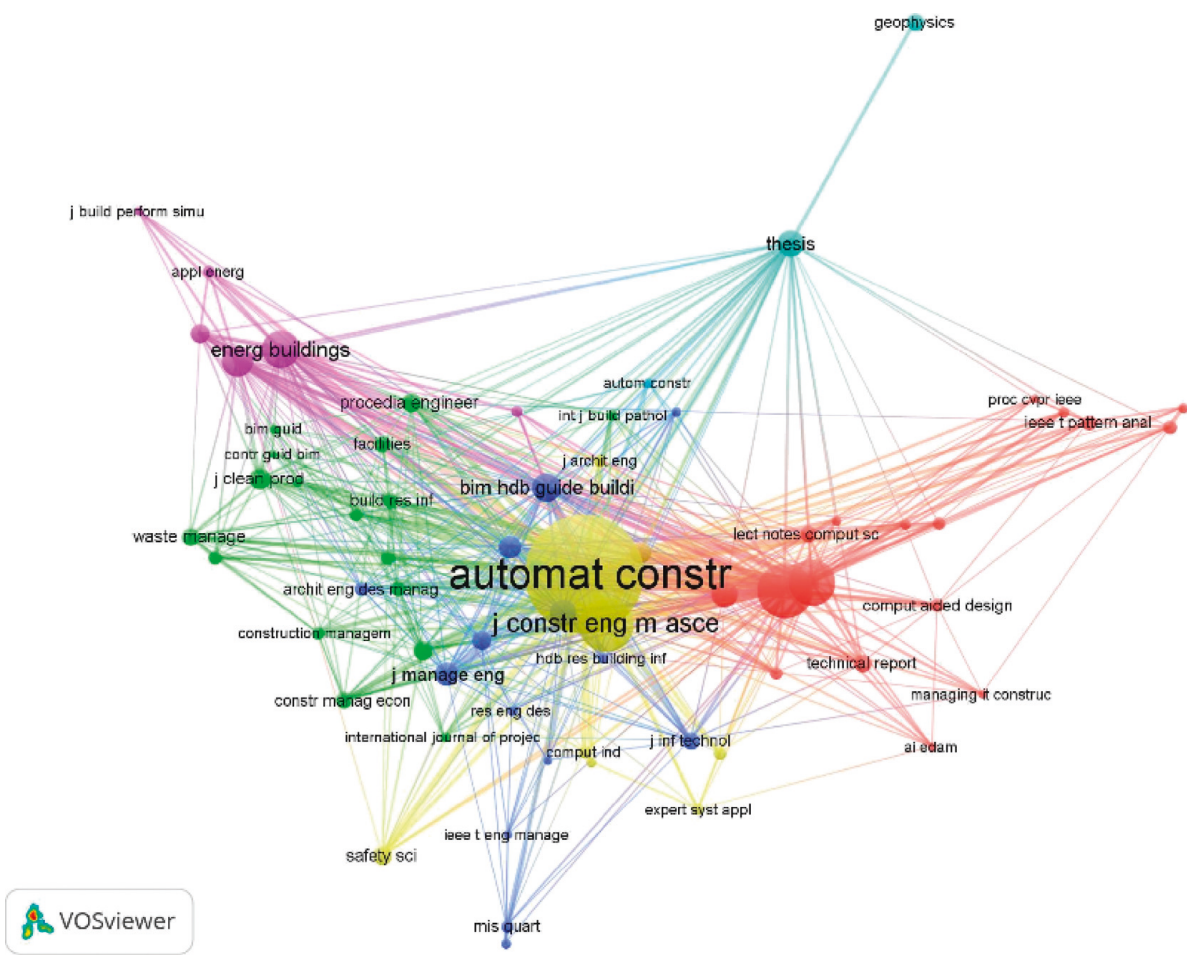

FIgURE 3: The main outlet networks describing the "Automation in Construction" as the most effective journal on the topic of integration in BbCNs.

from Figure 4 stated that technology-oriented studies received much more attention than those focusing on integration.

Accordingly, the author keywords' cooccurrence network confirms the discovery of the relevant outlets, and integration is hardly resolved from PM perspective within the body of knowledge on integration in BbCNs. This conclusion is made from the absence of a direct links between the two nodes and the distance between those nodes on the network as shown in Figure 4. 


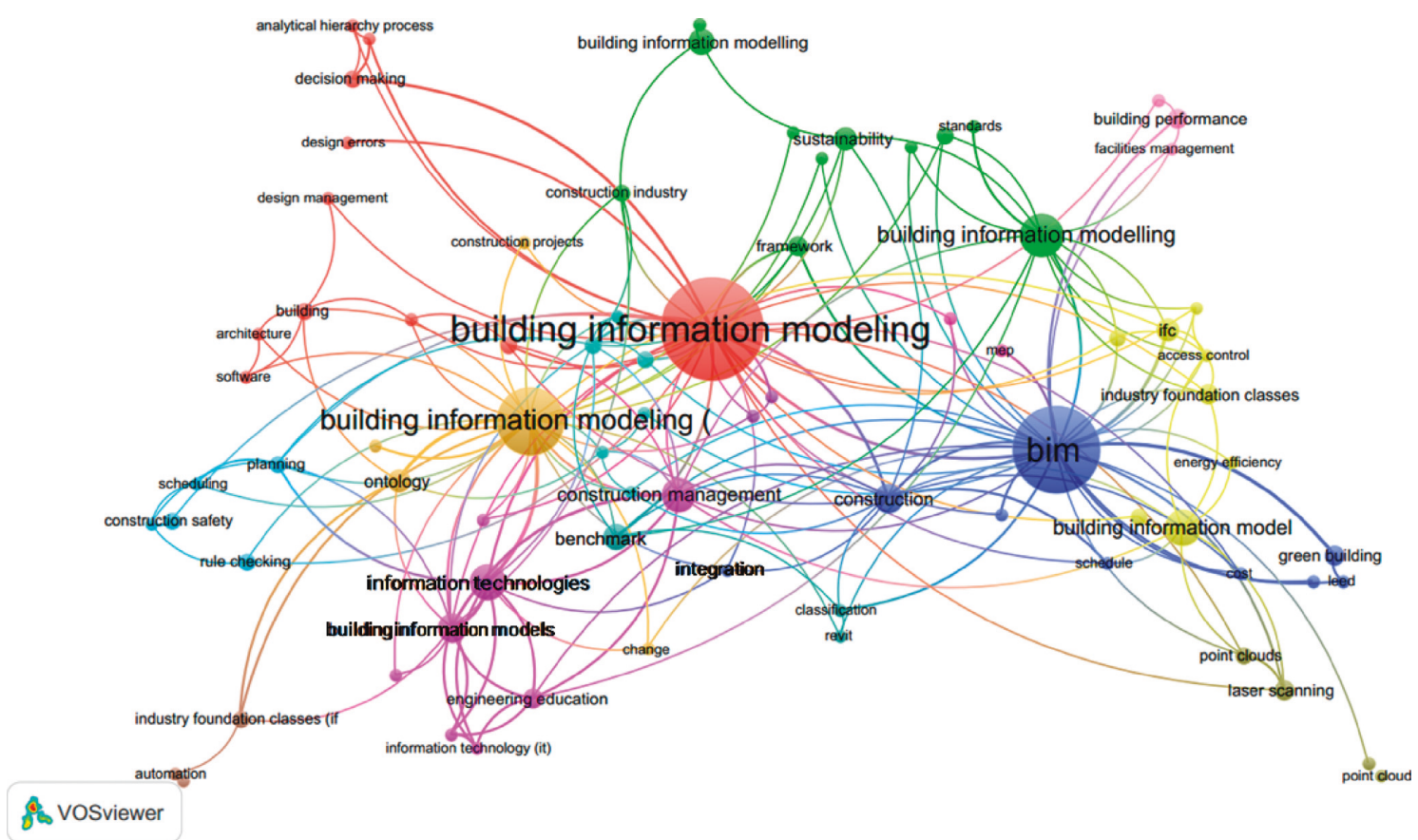

FIGURE 4: The cooccurrence network of keywords for the studies on integration in BbCNs describing the nodes of benchmark, construction, and information technologies closely related to integration.

3.2. Qualitative Analysis of the Literatures Associated with Integration in $\mathrm{BbCNs}$. To reduce the scope of the dataset and recognize researches relevant to integration directly, all 90 recognized documents have been reviewed to discover their major points. Each study has thoroughly been reviewed upon "integration pentagon" by at least two times to determine their relevance with the integration in BbCNs. A total of 42 articles were identified and covered in qualitative analysis shown in Table 1.

As affirmed by Abbas et al. [55], "coding is the beginning form in any kind of qualitative analysis, and also the basis of the later." One forward-thinking method of coding is to concentrate on the contrast, similarity, and comparison with an existing model or framework to frame the corresponding explanation [40]. In this study, the coding list of the all 42 articles is made on the basis of the integration pentagon as illustrated in Figure 1. The researches reviewed all 42 articles and allocated the content to the codes presented in Figure 1. The classification results of the content is shown in Table 1, which clearly illustrates the focus of the selected literatures and allows researchers to spot the differences easily.

3.3. Context Dimension of Integration in BbCNs. Eight studies ( $20 \%$ of the total) focus on the context dimension in influencing the integration in $\mathrm{BbCNs}$, registering the highest rate among all dimensions in this review. Context dimension refers to the environment conducive to the development of integration in BbCNs. It is necessary to provide a fertile soil for plant growth; likewise, it is important to nurture a supportive environment to enhance integration in BbCNs $[5,53]$. In this sense, the focus of the articles highlighting "context" dimension is to identify the major driving forces to nurture a supportive environment [38].

Grilo and Jardim-Goncalves [27], Fadeyi [54], Jacobsson and Linderoth [49], and Demirkesen and Ozorhon [12] brought to light the central role of an encouraging organizational environment good for integration, affecting BbCNs as socio-organizational factors. Studies falling in this category also figured out a favorable context to develop the integration in BbCNs, including improving BIM education [55], exerting positive influence from the culture [49], and building up a needed legal framework to consummate the organizational environment. Accordingly, three key barriers to integration are the concept, and knowledge of interorganizational integration is the key skill that should be incorporated into the BIM education programs [55]. In addition, resisting the change from traditional work practices, adapting to innovative technologies, takes a long time, lacking understanding of the processes and workflows required by BIM [28, 56, 76, 77].

By studying the existing researches, we can get the enlightenment that the key work of cultivating a supportive environment to enhance integration in $\mathrm{BbCNs}$ lies in transforming the traditional thinking patterns of organizational division of labor. The impact of education and policy laws accelerates the shift by making the participants in $\mathrm{BbCNs}$ realize that the integration and BIM are more than just a tool, but an important innovation of organizational model is driven by a multiwin business strategy. In future researches, more attention should be attached to the strategies and mechanisms promoting the transformation of thinking patterns. 
TABLE 1: Study associated with integration in BbCNs and the dimensions targeted in each study.

\begin{tabular}{|c|c|c|}
\hline ID & $\begin{array}{l}\text { Study associated with } \\
\text { integration in BbCNs }\end{array}$ & $\begin{array}{c}\text { Dimensions of integration } \\
\text { pentagon }\end{array}$ \\
\hline 1 & Akintola et al. [47] & Actor \\
\hline 2 & Demirkesen and Ozorhon [12] & Actor/context \\
\hline 3 & Habibi $[48]$ & Actor \\
\hline 4 & Jacobsson and Linderoth [49] & Actor/context \\
\hline 5 & Linderoth $[13]$ & Actor \\
\hline 6 & Ozorhon et al. [50] & Actor \\
\hline 7 & Rahman et al. [51] & Actor \\
\hline 8 & Shao [52] & Actor \\
\hline 9 & Poirier et al. [53] & Context \\
\hline 10 & Liu et al. [5] & Context/process \\
\hline 11 & Fadeyi [54] & Context \\
\hline 12 & Abbas et al. [55] & Context \\
\hline 13 & Grilo and Jardim-Goncalves [27] & Context/process \\
\hline 14 & Babič et al. [56] & Context \\
\hline 15 & Gemünden et al. [57] & Organization \\
\hline 16 & Eskerod and Larsen [58] & Organization \\
\hline 17 & Wen and Qiang [59] & Organization/task \\
\hline 18 & Oti et al. [60] & Organization \\
\hline 19 & Mignone et al. [61] & Organization \\
\hline 20 & Al Mousli and El-Sayegh [17] & Organization \\
\hline 21 & Son et al. [62] & Organization \\
\hline 22 & Berteaux and Javernick-Will [30] & Organization \\
\hline 23 & Whyte and Hartmann [63] & Organization \\
\hline 24 & Ajam et al. [64] & Organization/process \\
\hline 25 & Solihin et al. [23] & Process \\
\hline 26 & Dave et al. [65] & Process \\
\hline 27 & Ahola et al. [11] & Process \\
\hline 28 & Ilhan and Yaman [66] & Process \\
\hline 29 & Forgues et al. [67] & Process \\
\hline 30 & Amann and Borrmann [45] & Process \\
\hline 31 & Tarandi $[68]$ & Process \\
\hline 32 & Arayici et al. [69] & Process \\
\hline 33 & Zhang et al. [70] & Process \\
\hline 33 & Wang et al. [29] & Process \\
\hline 34 & Ding et al. [71] & Process \\
\hline 35 & Yi et al. [6] & Process \\
\hline 36 & London and Singh [72] & Process \\
\hline 37 & Chen et al. [18] & Process/task \\
\hline 38 & Sanguinetti et al. [73] & Process \\
\hline 39 & Singh et al. [74] & Process \\
\hline 40 & Gassel et al. [19] & Task \\
\hline 41 & Papadonikolaki et al. [2] & Task \\
\hline 42 & Shin [75] & Task \\
\hline
\end{tabular}

3.4. Actor Dimension of Integration in BbCNs. Implementation of a new technology inevitably leads to the emergence of new work roles of the individual team members [39]. As Azhar [78] said, BIM represents a new paradigm within AEC, one that encourages integration of the roles of all stakeholders on a project. As illustrated in Table 1, 8 studies (20\%) focus on the roles of BbCN actor. These studies in this category show that the present organizational actors were not supportive of the concomitant process changes associated with new technological solutions [79] because in effect, the changes intrinsic to BIM implementation is substantial and it necessitates new set of skills and new ways of thinking.
Consequently, the roles of $\mathrm{BbCNs}$, which are relevant for supporting BbCNs-enabled project, have been identified: include not only technical competencies bus also skills related to process changes and management [47, 48, 51]. Concerning expectations of the characteristics of a BbCNs actor, these researches had relatively similar opinions that are made in these researches. Besides, there seems a high expectation on the characteristics of a BbCNs actor, especially in terms of excellent interpersonal skills, commitment, and leadership in the study of Jacobsson and Linderoth [49] and Linderoth [13]. Bosch-Sijtsema et al. [80] and Shao [52] compared the similarities and significant differences between BIM and non-BIM actors in characteristics, experiences, and education and found that BIM actors considered their roles, characteristics, and education as coordinating and pushing for change.

In conclusion, we find that the data from these studies provide insights into the level of professional competence of the BbCNs actor. Nevertheless, there has been scant research on the responsibilities and obligations of $\mathrm{BbCN}$-related roles. Given present incomplete researches, one might conclude that a systematic study on the topic of the BbCNs actor is of necessity.

3.5. Process Dimension of Integration in $\mathrm{BbCNs}$. As shown in Table 1, 18 studies explore the importance of process on integration in BbCNs. This subsystem involves business processes and the technologies (tools, techniques, machines, etc.) with functionalities to perform required processes and enhance the overall performance of the system [71, 72, 74]. Studies falling in this category such as Uhm et al. [81], Liu et al. [5], Takim et al. [82], and Succar [83] underline the use of software and tools as required processes to support integration in BbCNs.

Solihin et al. [23] proposed a framework that can more fully integrate different models into an integrated model in a federated environment. Liu et al. [5] stated that the reliable network-based systems are conducive to achieving successful integration. Amann and Borrmann [45], Ajam et al. [64], Sanguinetti et al. [73], and Yi et al. [6] identified that cloud-based platforms are of a great potential for integrating models, simulating components, and providing seamless data sharing for end users in BbCNs. Ahola et al. [11] and Arayici et al. [69] proposed an interoperability specification development approach for intergraded BIM use in performance-based design. Zhang et al. [70], Dave et al. [65], and Ilhan and Yaman [66] also proposed a multiserver information sharing with a private cloud after analyzing the requirements for cross-party integration in a BIM scenario.

Scholars, however, came upon different points of view. Just as what has been described by Grilo et al. [84], process integration cannot be simply regarded as a result of cloudbased tools and coordination and collaboration among stakeholders are equally important. In terms of this arguments, we propose that the follow-up researches into process integration should focus on both technology and management perspectives. 
3.6. Organization Dimension of Integration in BbCNs. Following the presentation in Table 1, 10 studies stress the importance of organization on integration in BbCNs. Organizational dimension is to integrate a set of participants with different functions into an organic organization. Arayici et al. [69] stated that the problem of interoperability between organizations exists in many areas where collaboration, interaction, and data exchange are required. This is especially suitable for the construction, engineering and construction (AEC) fields, where the evolution of practice and the BIM paradigm have reinforced the need for integration among different stakeholders.

Whyte and Hartmann [63], Gemünden et al. [57], and Oti et al. [60] found that BIM become a "cultural driver" for integration, and each partner in the BIM-enabled project will bring new aspects to the project organization, which will require organization changes in how BIM is applied and used. The findings present in the literature work in this category suggest that the redefining work roles $[9,85]$ and designing relationships [30] have been considered as positive factors to support organizational integration. In addition, some scholars have proposed that establishing the mechanism of benefit conforming and contradiction handling contribute to can effectively improve the level of trust and then promote the cooperation of participants $[17,59,61]$.

Building on the discussions above, the future research on organization dimension is expected: (1) investigate the contract forms of BbCNs, (2) identify the supportive organizational structures, and (3) follow a multisystem thinking of a governance model.

3.7. Task Dimension of Integration in BbCNs. As inferred from Table 1, 5 studies explore integration from microperspective, focusing on the importance of tasks on integration in BbCNs. In these studies, discussions are made on the potential impact of tasks performed by a BbCNs and how they influence team functioning and effectiveness $[75,81]$. An interesting result is that seemingly low volume of papers addresses the actor aspect of BbCNs, this being referred to as one of the best aspects of BbCNs, though.

Literatures in this category attach important specific tasks and activities of integration in BbCNs, such as integrated knowledge, integrated changes, and integrated production factors. As illustrated by Chen et al. [18], Xue et al. [77], and Wen and Qiang [59], integrated knowledge is definitely essential for fulfilling integration in BbCNs. This is because knowledge disclosure would result in repetitive work and waste, lack of innovation and thus leads to organization inefficiency. The studies by Gassel et al. [19] proved that the integration of changes lends to fewer obstacle for information transmission and less time for information interaction between participants, thus making the change more time sensitive. The findings also indicate that BbCNs could not only support the project development process as a systematic management tool but also serve as a core data generator and platform allowing other participants to perform further tasks.
Generally, previous researchers into task dimension highlight the tasks required to implement BbCNs, yet with insufficient details, i.e., there shows a lack of more detailed research. Such as a lack of research on how task types and task complexity influence the performance of $\mathrm{BbCNs}$ implementation.

\section{Implications of the Findings}

Identifying further strategies for BbCNs is an intriguing area for future research. Based on the scientmetric analysis, some fundamental viewpoints and frontier insights with respect to the existing literatures into integration in $\mathrm{BbCNs}$ have been developed. Systematic mixed-methods allow us to review the available literatures on BIM, and the result suggests that integration is a core element in the BIM literature. Although the potential value of integration in advancing successful BIM-based projects have been accepted [9], the research into integration in $\mathrm{BbCNs}$ has not received enough attention it deserves (Figure 2). The findings also show that previous studies mainly explored integration in BbCNs from a technology-oriented orientation (Figure 3). Although BIM is a sociotechnical system [5], the research into BIM has not been carried out from the managerial perspective, and deficient focus has been made on social-related features of integration within $\mathrm{BbCNs}$ [9]. Such a research situation runs counter to the widely held view in the industrial sector that "successful integration originates from $80 \%$ of people and $20 \%$ of the technology or information." It shows that the future research into integration in BbCNs must shift the focus to the managerial areas.

To reach the study objective, a qualitative analysis based on integration pentagon is conducted to exam and demonstrate the current status and future directions of integration in BbCNs. The findings call for future research to target these dimensions such as context, tasks, actors, and organization, which are currently under-represented in studies exploring integration in BbCNs. The findings magnified the gap in the study of context dimension so that future research is expected to cultivate the incentive mechanism for promoting the enthusiasm of participants to implement BbCNs in project management practice. The research gaps related to the actor dimension call for a systematic research to identify the responsibilities and obligations of BbCNs-related roles. As for the organization dimension, three components including the contract forms of BbCNs, a multisystem thinking of the governance model, and the supportive organizational structures should receive attention. The challenge the existing studies of task dimension confronts is that implementing $\mathrm{BbCNs}$ often requires a specific environment, so the future research in this regard must be highly bespoke and context specific. In other words, future research on task dimension should take into account its interrelationships with organizational context, structures, roles, and other elements.

In addition, the outcome of this study also reveals that existing BIM researches explore integration from a fragmented and disjointed way. Namely, isolated antecedents are observed in various researches with little paying no attention 
to the importance of associations and the synergy between these antecedents. These antecedents' dimensions of integration in $\mathrm{BbCNs}$ have rarely been considered as necessary components of a unified system. There is a lack of necessary attention to reflect how the integration is affected by misalignment between these dimensions. Even if Leavitt had earlier argued for the interrelatedness of these sociotechnical system dimensions and for the need for Aa comprehensive consideration. These conclusions consequently lead to a call for more studies that examine the interacting impacts and synergy among the interrelated integration dimensions in BbCNs.

\section{Conclusions and Future Research}

Although enhancing integration in BbCNs has been a wellrecognized problem, this study explores the problem in an all-round way. This study has drawn findings from a batch of literature works comprising 42 studies. A systematic mixedmethod review was used to analyze the storyline of research studies relevant to integration in $\mathrm{BbCNs}$. The results provide a solid foundation for the research of integration in BbCNs. Moreover, this study also extends the scope of research into integration in BbCNs by focusing on the significance of social components. The primary theoretical and methodological contribution made by this study to the body of knowledge of integration in $\mathrm{BbCNs}$ can be summed up in three aspects.

First, this study maps a research area of integration in $\mathrm{BbCNs}$ based on the knowledge base, domains, and evolution by using a systematic mixed-method review. The study results highlight how the research of integration of $\mathrm{BbCNs}$ evolves, thus greatly contributing to understanding the status quo of BIM knowledge. The methods presented detailed in this study can be generalized and used as an effective tool for mapping discipline knowledge. It is recommended that future studies should be conducted periodically to improve the $\mathrm{BOK}$ of $\mathrm{BbCNs}$ provided in this study.

Second, in this study, an extended Leavitt sociological model was used for reference to build an integration pentagon which was made up of context, process, organization, task and actor. The integration pentagon is used as the conceptualization theoretical lens offering researchers to identify the existing gaps in the literature regarding the integration in $\mathrm{BbCNs}$ and providing a theoretical foundation to test and guide future research. The integration pentagon also enhances our comprehension of the integration antecedents for BbCNs by emphasizing the essentiality of pondering these enablers from an all in view.

More importantly, these findings provide a valuable reference to the developers of $\mathrm{BbCNs}$ to understand the major barriers in their decision-making and to government aiming at promoting $\mathrm{BIM}$ or $\mathrm{BbCNs}$ in the construction industry with relevant policies and incentives.

Despite that the contributions of this study have been mentioned, some of the study limitations must be acknowledged before applying the findings. First, the research is made merely based on WoS publications. Another limitation involves generalization, which is a result of using specific keywords which may omit the relevant research. In addition, the integration pentagon, which has been used to match and encode studies on integration, could be considered subjective in nature. In future studies, this may occur by incorporating members to check validation processes to enhance the credibility. In addition, a lack of publications in available databases also affected the results of bibliometric analysis.

\section{Conflicts of Interest}

The authors declare that they have no conflicts of interest.

\section{References}

[1] R. Jin, C. M. Hancock, L. Tang, and D. Wanatowski, "BIM investment, returns, and risks in China's AEC industries," Journal of Construction Engineering and Management, vol. 143, no. 12, article 04017089, 2017.

[2] E. Papadonikolaki, R. Vrijhoef, and H. Wamelink, "The interdependences of BIM and supply chain partnering: empirical explorations," Architectural Engineering \& Design Management, vol. 12, no. 6, pp. 476-494, 2016.

[3] A. Grilo and R. Jardim-Goncalves, "Cloud-marketplaces: distributed e-procurement for the AEC sector," Advanced Engineering Informatics, vol. 27, no. 2, pp. 160-172, 2013.

[4] D. Cao, H. Li, G. Wang, and T. Huang, "Identifying and contextualising the motivations for BIM implementation in construction projects: an empirical study in China," International Journal of Project Management, vol. 35, no. 4, pp. 658-669, 2017.

[5] Y. Liu, S. van Nederveen, and M. Hertogh, "Understanding effects of BIM on collaborative design and construction: an empirical study in China," International Journal of Project Management, vol. 35, no. 4, pp. 686-698, 2017.

[6] J. Yi, Y. Wang, S. Zhang, L. Yin, B. Yang, and Y. Lei, “A cloud approach to unified lifecycle data management in architecture, engineering, construction and facilities management: integrating BIMs and SNS," Advanced Engineering Informatics, vol. 27, no. 2, pp. 173-188, 2013.

[7] M. T. Shafiq, J. Matthews, and S. R. Lockley, "A study of BIM collaboration requirements and available features in existing model collaboration systems," Journal of Information Technology in Construction, vol. 18, pp. 148-161, 2013.

[8] E. Alreshidi, M. Mourshed, and Y. Rezgui, "Requirements for cloud-based BIM governance solutions to facilitate team collaboration in construction projects," Requirements Engineering, vol. 23, no. 1, pp. 1-31, 2016.

[9] H. M. Reza, B. Saeed, C. Nicholas et al., "BIM adoption within Australian small and medium-sized enterprises (SMEs): an innovation diffusion model," Construction Economics and Building, vol. 16, no. 3, pp. 71-86, 2016.

[10] M. Oraee, M. R. Hosseini, E. Papadonikolaki, R. Palliyaguru, and M. Arashpour, "Collaboration in BIM-based construction networks: a bibliometric-qualitative literature review," International Journal of Project Management, vol. 35, no. 7, pp. 1288-1301, 2017.

[11] T. Ahola, M. Vuori, and E. Viitamo, "Sharing the burden of integration: an activity-based view to integrated solutions provisioning," International Journal of Project Management, vol. 35, no. 6, pp. 1006-1021, 2017. 
[12] S. Demirkesen and B. Ozorhon, "Impact of integration management on construction project management performance," International Journal of Project Management, vol. 35, no. 8, pp. 1639-1654, 2017.

[13] H. C. J. Linderoth, "Understanding adoption and use of BIM as the creation of actor networks," Automation in Construction, vol. 19, no. 1, pp. 66-72, 2010.

[14] M. Löwstedt, C. Räisänen, and R. Leiringer, "Doing strategy in project-based organizations: actors and patterns of action," International Journal of Project Management, vol. 36, no. 6, pp. 889-898, 2018.

[15] C. Merschbrock, M. R. Hosseini, I. Martek, M. Arashpour, and G. Mignone, "Collaborative role of sociotechnical components in BIM-based construction networks in two hospitals," Journal of Management in Engineering, vol. 34, no. 4, article 05018006, 2018.

[16] R. M. Dowsett and C. F. Harty, "Assessing the implementation of BIM-an information systems approach," Construction Management and Economics, pp. 1-16, 2018.

[17] M. H. Al Mousli and S. M. El-Sayegh, "Assessment of the design-construction interface problems in the UAE," Architectural Engineering and Design Management, vol. 12, no. 5, pp. 353-366, 2016.

[18] S. M. Chen, F. H. Griffis, P. H. Chen, and L. M. Chang, "A framework for an automated and integrated project scheduling and management system," Automation in Construction, vol. 35, no. 11, pp. 89-110, 2013.

[19] F. J. M. V. Gassel, T. Láscaris-Comneno, and G. J. Maas, “The conditions for successful automated collaboration in construction," Automation in Construction, vol. 39, pp. 85-92, 2014.

[20] S. K. Lee and J. H. Yu, "Success model of project management information system in construction," Automation in Construction, vol. 25, pp. 82-93, 2012.

[21] E. Papadonikolaki and H. Wamelink, "Inter- and intraorganizational conditions for supply chain integration with BIM," Building Research \& Information the International Journal of Research Development \& Demonstration, vol. 45, no. 1, pp. 1-16, 2017.

[22] J. Whyte, A. Stasis, and C. Lindkvist, "Managing change in the delivery of complex projects: configuration management, asset information and "big data", International Journal of Project Management, vol. 34, no. 2, pp. 339-351, 2016.

[23] W. Solihin, C. Eastman, and Y. Lee, "A framework for fully integrated building information models in a federated environment," Advanced Engineering Informatics, vol. 30, no. 2, pp. 168-189, 2016.

[24] T. R. Browning, "Managing complex project process models with a process architecture framework," International Journal of Project Management, vol. 32, no. 2, pp. 229-241, 2014.

[25] A. Butt, M. Naaranoja, and J. Savolainen, "Project change stakeholder communication," International Journal of Project Management, vol. 34, no. 8, pp. 1579-1595, 2016.

[26] D. Gough, "Qualitative and mixed methods in systematic reviews," Systematic Reviews, vol. 4, no. 1, pp. 1-3, 2015.

[27] A. Grilo and R. Jardim-Goncalves, "Value proposition on interoperability of BIM and collaborative working environments," Automation in Construction, vol. 19, no. 5, pp. 522530, 2010.

[28] R. Eadie, M. Browne, H. Odeyinka, C. McKeown, and S. McNiff, "A survey of current status of and perceived changes required for BIM adoption in the UK," Built Environment Project and Asset Management, vol. 5, no. 1, pp. 4-21, 2015.
[29] W. C. Wang, S. W. Weng, S. H. Wang, and C. Y. Chen, "Integrating building information models with construction process simulations for project scheduling support," Automation in Construction, vol. 37, no. 6, pp. 68-80, 2014.

[30] F. Berteaux and A. Javernick-Will, "Adaptation and integration for multinational project-based organizations," Journal of Management in Engineering, vol. 31, no. 6, article 04015008, 2015.

[31] M. Gibbert, W. Ruigrok, and B. Wicki, "What passes as a rigorous case study?," Strategic Management Journal, vol. 29, no. 13, pp. 1465-1474, 2008.

[32] R. P. Bostrom, S. Gupta, and D. Thomas, “A meta-theory for understanding information systems within sociotechnical systems," Journal of Management Information Systems, vol. 26, no. 1, pp. 17-48, 2009.

[33] S. Alter, "The work system method for understanding information systems and information systems research," Communications of the Association for Information Systems, vol. 9, 2002.

[34] H.-J. Bargstädt, "Challenges of BIM for construction site operations," Procedia Engineering, vol. 117, pp. 52-59, 2015.

[35] E. Sackey, M. Tuuli, and A. Dainty, "Sociotechnical systems approach to BIM implementation in a multidisciplinary construction context," Journal of Management in Engineering, vol. 31, no. 1, article A4014005, 2015.

[36] H. J. Leavitt, "Applied organization change in industry: structural, technical and human approaches," Experimental Brain Research, vol. 45, no. 1-2, pp. 1-12, 1964.

[37] K. Davis, "Different stakeholder groups and their perceptions of project success," International Journal of Project Management, vol. 32, no. 2, pp. 189-201, 2014.

[38] E. Poirier, D. Forgues, and S. Staub-French, "Collaboration through innovation: implications for expertise in the AEC sector," Construction Management and Economics, vol. 34, no. 11, pp. 769-789, 2016.

[39] Q. He, G. Wang, L. Luo, Q. Shi, J. Xie, and X. Meng, "Mapping the managerial areas of Building information modeling (BIM) using scientometric analysis," International Journal of Project Management, vol. 35, no. 4, pp. 670-685, 2017.

[40] K. Lyytinen and M. Newman, "Explaining information systems change: a punctuated socio-technical change model," European Journal of Information Systems, vol. 17, no. 6, pp. 589-613, 2008.

[41] W. Aarseth, T. Ahola, K. Aaltonen, A. Økland, and B. Andersen, "Project sustainability strategies: a systematic literature review," International Journal of Project Management, vol. 35, no. 6, pp. 1071-1083, 2017.

[42] C. Ke, W. Lu, P. Yi, S. Rowlinson, and G. Q. Huang, "Bridging BIM and building: from a literature review to an integrated conceptual framework," International Journal of Project Management, vol. 33, no. 6, pp. 1405-1416, 2015.

[43] N. J. V. Eck and L. Waltman, "Software survey: VOSviewer, a computer program for bibliometric mapping," Scientometrics, vol. 84, no. 2, pp. 523-538, 2010.

[44] A. M. Mahamadu, L. Mahdjoubi, and C. Booth, "Challenges to BIM-cloud integration: implication of security issues on secure collaboration," Journal of Endocrinological Investigation, vol. 28, no. 7, pp. 425-431, 2013.

[45] J. Amann and A. Borrmann, "Embedding procedural knowledge into building information models: the IFC procedural language and its application for flexible transition curve representation," Journal of Computing in Civil Engineering, vol. 30, no. 5, article C4016006, 2016. 
[46] Z. Riaz, M. Arslan, A. K. Kiani, and S. Azhar, "CoSMoS: a BIM and wireless sensor based integrated solution for worker safety in confined spaces," Automation in Construction, vol. 45, pp. 96-106, 2014.

[47] A. Akintola, S. Venkatachalam, and D. Root, "New BIM roles' legitimacy and changing power dynamics on BIM-enabled projects," Journal of Construction Engineering and Management, vol. 143, no. 9, article 04017066, 2017.

[48] S. Habibi, "The promise of BIM for improving building performance," Energy and Buildings, vol. 153, pp. 525-548, 2017.

[49] M. Jacobsson and H. C. J. Linderoth, "The influence of contextual elements, actors' frames of reference, and technology on the adoption and use of ICT in construction projects: a Swedish case study," Construction Management \& Economics, vol. 28, no. 1, pp. 13-23, 2010.

[50] B. Ozorhon, C. Abbott, and G. Aouad, "Integration and leadership as enablers of innovation in construction: case study," Journal of Management in Engineering, vol. 30, no. 2, pp. 256-263, 2014.

[51] R. A. Rahman, S. Alsafouri, P. Tang, and S. K. Ayer, "Comparing building information modeling skills of project managers and BIM managers based on social media analysis," Procedia Engineering, vol. 145, pp. 812-819, 2016.

[52] J. Shao, "The moderating effect of program context on the relationship between program managers' leadership competences and program success," International Journal of Project Management, vol. 36, no. 1, pp. 108-120, 2018.

[53] E. A. Poirier, D. Forgues, and S. Staubfrench, "Understanding the impact of BIM on collaboration: a Canadian case study," Building Research \& Information, vol. 45, no. 6, pp. 681-695, 2017.

[54] M. O. Fadeyi, "The role of building information modeling (BIM) in delivering the sustainable building value," International Journal of Sustainable Built Environment, vol. 6, no. 2, pp. 711-722, 2017.

[55] A. Abbas, Z. U. Din, and R. Farooqui, "Integration of BIM in construction management education: an overview of Pakistani engineering universities," Procedia Engineering, vol. 145, pp. 151-157, 2016.

[56] N. Č. Babič, P. Podbreznik, and D. Rebolj, "Integrating resource production and construction using BIM," Automation in Construction, vol. 19, no. 5, pp. 539-543, 2010.

[57] H. G. Gemünden, P. Lehner, and A. Kock, "The projectoriented organization and its contribution to innovation," International Journal of Project Management, vol. 36, no. 1, pp. 147-160, 2018.

[58] P. Eskerod and T. Larsen, "Advancing project stakeholder analysis by the concept "shadows of the context"," International Journal of Project Management, vol. 36, no. 1, pp. 161-169, 2018.

[59] Q. Wen and M. Qiang, "Coordination and knowledge sharing in construction project-based organization: a longitudinal structural equation model analysis," Automation in Construction, vol. 72, pp. 309-320, 2016.

[60] A. H. Oti, W. Tizani, F. H. Abanda, A. Jaly-Zada, and J. H. M. Tah, "Structural sustainability appraisal in BIM," Automation in Construction, vol. 69, pp. 44-58, 2016.

[61] G. Mignone, M. R. Hosseini, N. Chileshe, and M. Arashpour, "Enhancing collaboration in BIM-based construction networks through organisational discontinuity theory: a case study of the new Royal Adelaide Hospital," Architectural Engineering \& Design Management, vol. 12, no. 5, pp. 333352,2016
[62] H. Son, S. Lee, and C. Kim, "What drives the adoption of building information modeling in design organizations? An empirical investigation of the antecedents affecting architects' behavioral intentions," Automation in Construction, vol. 49, no. 8, pp. 92-99, 2015.

[63] J. K. Whyte and T. Hartmann, "How digitizing building information transforms the built environment," Building Research \& Information, vol. 45, no. 6, pp. 591-595, 2017.

[64] M. Ajam, M. Alshawi, and T. Mezher, "Augmented process model for e-tendering: towards integrating object models with document management systems," Automation in Construction, vol. 19, no. 6, pp. 762-778, 2010.

[65] B. Dave, A. Buda, A. Nurminen, and K. Främling, "A framework for integrating BIM and IoT through open standards," Automation in Construction, vol. 95, pp. 35-45, 2018.

[66] B. Ilhan and H. Yaman, "Green building assessment tool (GBAT) for integrated BIM-based design decisions," Automation in Construction, vol. 70, pp. 26-37, 2016.

[67] E. C. Forgues, V. Carignan, D. Forgues, and S. B. Rajeb, “A framework for improving collaboration patterns in BIM projects," in Proceedings of the International Conference on Cooperative Design, Sydney, Australia, October 2016.

[68] V. Tarandi, "A BIM collaboration lab for improved through life support," Procedia Economics \& Finance, vol. 21, pp. 383-390, 2015.

[69] Y. Arayici, T. Fernando, V. Munoz, and M. Bassanino, "Interoperability specification development for integrated BIM use in performance based design," Automation in Construction, vol. 85, pp. 167-181, 2018.

[70] J. Zhang, Q. Liu, Z. Hu, J. Lin, and F. Yu, “A multi-server information-sharing environment for cross-party collaboration on a private cloud," Automation in Construction, vol. 81, pp. 180-195, 2017.

[71] L. Ding, Y. Zhou, and B. Akinci, "Building information modeling (BIM) application framework: the process of expanding from $3 \mathrm{D}$ to computable $\mathrm{nD}$," Automation in Construction, vol. 46, pp. 82-93, 2014.

[72] K. London and V. Singh, "Integrated construction supply chain design and delivery solutions," Architectural Engineering and Design Management, vol. 9, no. 3, pp. 135-157, 2013.

[73] P. Sanguinetti, S. Abdelmohsen, J. M. Lee, J. K. Lee, H. Sheward, and C. Eastman, "General system architecture for BIM: an integrated approach for design and analysis," Advanced Engineering Informatics, vol. 26, no. 2, pp. 317-333, 2012.

[74] V. Singh, N. Gu, and X. Wang, "A theoretical framework of a BIM-based multi-disciplinary collaboration platform," $A u$ tomation in Construction, vol. 20, no. 2, pp. 134-144, 2011.

[75] T.-S. Shin, "Building information modeling (BIM) collaboration from the structural engineering perspective," International Journal of Steel Structures, vol. 17, no. 1, pp. 205-214, 2017.

[76] A. Porwal and K. N. Hewage, "Building information modeling (BIM) partnering framework for public construction projects," Automation in Construction, vol. 31, pp. 204-214, 2013.

[77] X. Xue, Q. Shen, and Z. Ren, "Critical review of collaborative working in construction projects: business environment and human behaviors," Journal of Management in Engineering, vol. 26, no. 4, pp. 196-208, 2010.

[78] S. Azhar, "Building information modeling (BIM): trends, benefits, risks, and challenges for the AEC industry," 
Leadership \& Management in Engineering, vol. 11, no. 3, pp. 241-252, 2011.

[79] R. Sebastian, "Changing roles of the clients, architects and contractors through BIM," Engineering Construction \& Architectural Management, vol. 18, no. 2, pp. 176-187, 2011.

[80] P. M. Bosch-Sijtsema, P. Gluch, and A. A. Sezer, "Professional development of the BIM actor role," Automation in Construction, vol. 97, pp. 44-51, 2019.

[81] M. Uhm, G. Lee, and B. Jeon, "An analysis of BIM jobs and competencies based on the use of terms in the industry," Automation in Construction, vol. 81, pp. 67-98, 2017.

[82] R. Takim, M. Harris, and A. H. Nawawi, "Building information modeling (BIM): a new paradigm for quality of life within architectural, engineering and construction (AEC) industry," Procedia-Social and Behavioral Sciences, vol. 101, pp. 23-32, 2013.

[83] B. Succar, "Building information modelling framework: a research and delivery foundation for industry stakeholders," Automation in Construction, vol. 18, no. 3, pp. 357-375, 2009.

[84] A. Grilo, A. Zutshi, R. Jardim-Goncalves, and A. SteigerGarcao, "Construction collaborative networks: the case study of a building information modelling-based office building project," International Journal of Computer Integrated Manufacturing, vol. 26, no. 1-2, pp. 152-165, 2013.

[85] O. Salem, J. Solomon, A. Genaidy, and I. Minkarah, "Lean construction: from theory to implementation," Journal of Management in Engineering, vol. 22, no. 4, pp. 168-175, 2006. 


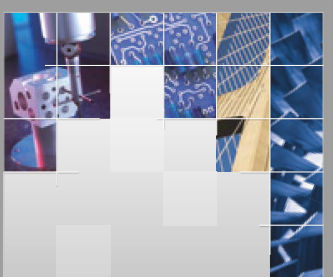

\section{Enfincering}
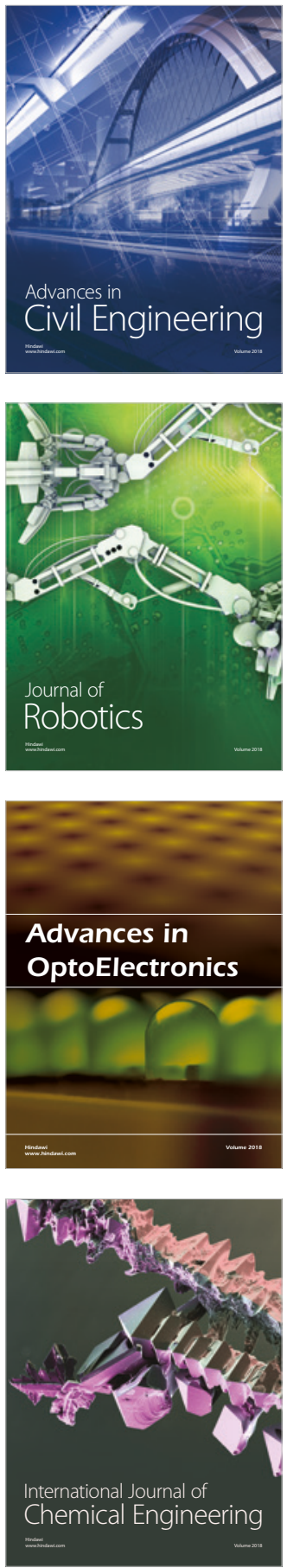

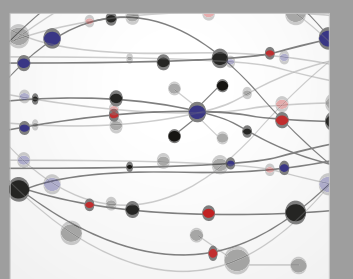

\section{Rotating \\ Machinery}

The Scientific World Journal

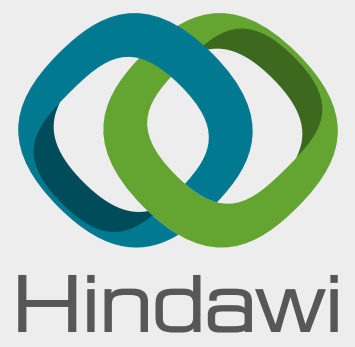

Submit your manuscripts at

www.hindawi.com
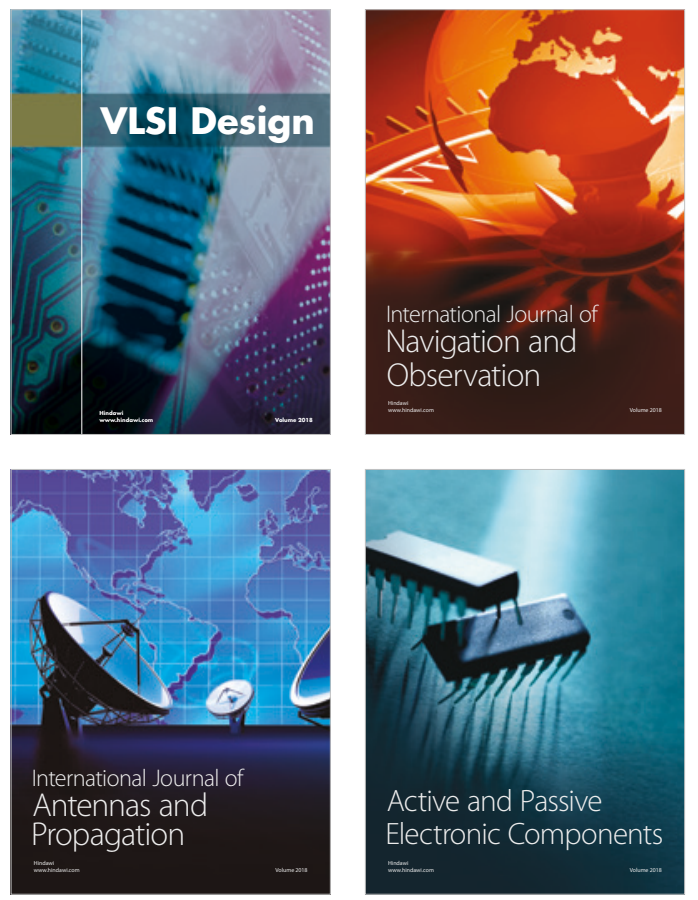
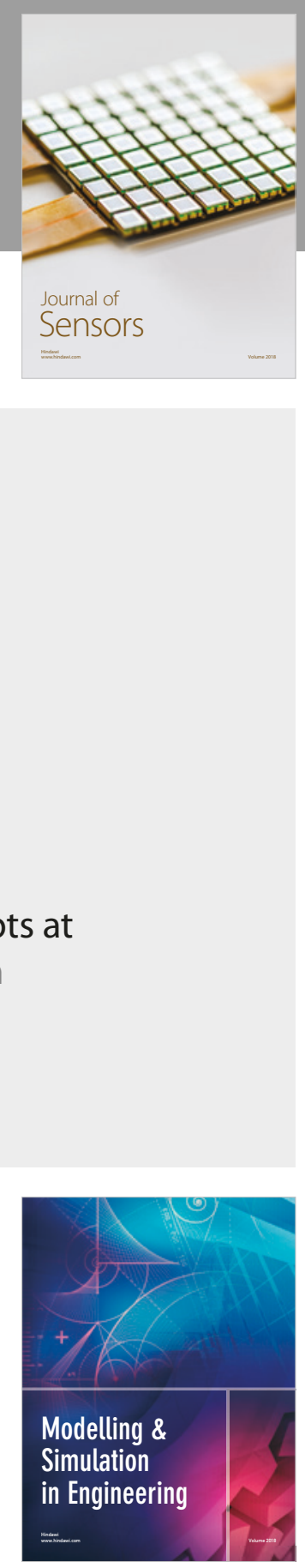

\section{Advances \\ Multimedia}
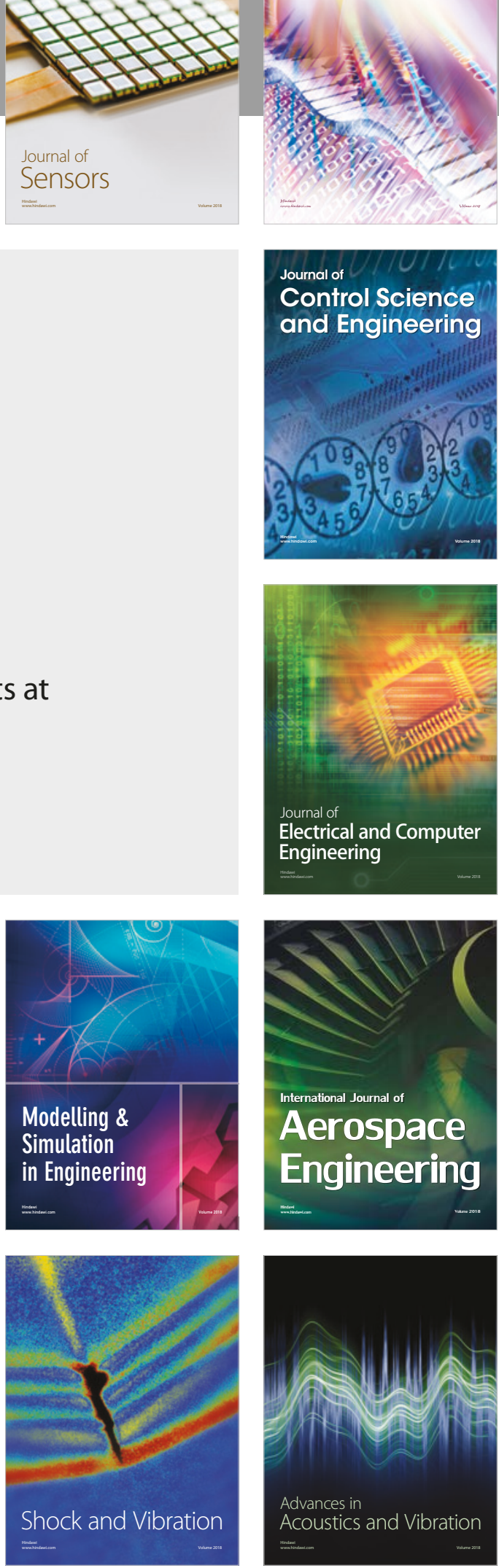